\title{
Deleterious Effect of Westernized Diet Pattern, Red Meat and High Salt Intake on Left Ventricular Structure and Function in Hypertensive Black Sub-Saharan Africans: A Multicentric Cross Sectional Study
}

\author{
Kianu Phanzu Bernard ${ }^{1,2, *}$, Nkodila Natuhoyila Aliocha ${ }^{3}$, Kokusa Zamani Roger ${ }^{4}$, Nzundu Tufuankenda Annie ${ }^{4}$, Limbole Baliko \\ Emmanuel $^{5}$, Kintoki Vita Eleuthère ${ }^{1}$, $\mathbf{M}^{\prime}$ buyamba Kabangu Jean-Réné ${ }^{1}$, and Longo-Mbenza Benjamin ${ }^{1}$
}

${ }^{1}$ Unit of Cardiology, University Hospital of Kinshasa, Kinshasa, Democratic Republic of Congo

${ }^{2}$ Centre Médical de Kinshasa (CMK), Pôle de Cardiologie, Kinshasa, Democratic Republic of Congo

${ }^{3}$ Public Health School, Department of Biostatistics, Kinshasa, Democratic Republic of Congo

${ }^{4}$ Provincial Reference Hospital of Kinshasa, Kinshasa, Democratic Republic of Congo

${ }^{5}$ Clinique Ngaliema, Kinshasa, Democratic Republic of Congo

*Corresponding author: Kianu Phanzu Bernard, Unit of Cardiology, University Hospital of Kinshasa, Kinshasa, Democratic Republic of Congo, Tel: +243 997622 019; E-mail: doctorkianu@gmail.com

Received: 29 Jun, 2021 | Accepted: 19 Jul, 2021 | Published: 26 Jul, 2021

Citation: Bernard KP, Aliocha NN, Roger KZ, Annie NT, Emmanuel LB, et al. (2021) Deleterious Effect of Westernized Diet Pattern, Red Meat and High Salt Intake on Left Ventricular Structure and Function in Hypertensive Black Sub-Saharan Africans: A Multicentric Cross Sectional Study. J Heart Health 7(2): dx.doi.org/10.16966/2379-769X.161

Copyright: (C) 2021 Bernard KP, et al. This is an open-access article distributed under the terms of the Creative Commons Attribution License, which permits unrestricted use, distribution, and reproduction in any medium, provided the original author and source are credited.

\section{Abstract}

Diet is one of the mosaics of environmental factors that can affect heart health. This impact, positive or negative, could occur through left ventricular remodeling.

Aims: To study the correlation between different specific foods and dietary patterns as well as dietary salt intake with left ventricular structure and function in hypertensive black Sub-Saharan Africans.

Methods: 77 apparently healthy Congolese black hypertensive participants were evaluated. Dietary sodium intakes were calculated based on the amount of sodium excreted in 24-hour urine. Dietary habits were assessed using a Food Frequency Questionnaire (FFQ). Left ventricular structure and function were assessed by cardiac doppler ultrasound using Vivid T8 (GE) ultrasound.

Results: There was a significant and negative linear correlation between fruit consumption per week and left ventricular end-diastolic diameter (LVED) ( $r=0.27, p=0.017)$, left ventricular mass (LVM) ( $r=0.23, p=0.047)$, left ventricular mass indexed to height ${ }^{2,7}(\mathrm{LVM} \mathrm{Ih})(\mathrm{r}=0.28, p=0.016)$, left ventricular mass indexed to body surface area (LVMIbsa) $(r=0.28, p=0.015)$ and deceleration time (DT) $(r=0.26, p=0.023)$; vegetable consumption per week and DT $(r=0.33, p=0.004)$; and fish consumption and $\operatorname{LVM}(r=0.25, p=0.030)$. There was a significant and positive linear correlation between fruit consumption and ratio of peak early and late diastolic flow velocities $(E / A)(r=0.28, p=0.013)$; meat consumption per week and Interventricular Septal Thickness (IVS) ( $r=0.27, p=0.016)$, sum of wall thickness (SWT) ( $r=0.26, p=0.013), \operatorname{LVM}(r=0.32, p=0.005)$, LVMIh ( $r=0.33, p=0.003)$ and LVMIbsa $(r=0.26, p=0.023)$; and fish consumption per week and LVMIh $(r=0.36, p=0.001) ; \mathrm{NaCl} g / 24 \mathrm{~h}$ and IVS $(r=0.29, p=0.012), P W T(r=0.33, p=0.003), S W T$ $(r=0.33, p=0.004)$, LVM $(r=0.34, p=0.002)$, LVMIh $(r=0.32, p=0.005)$, LVMIbsa $(r=0.36, p=0.001)$, RWT $(r=0.25, p=0.031)$ and left atrial area $(r=0.50$, $\mathrm{p}<0.001$ ). In a multiple linear regression analysis, fruit consumption, meat consumption and $\mathrm{NaCl} \mathrm{g} / 24 \mathrm{~h}$ were the independent determinants of LVM, LVMIh and LVMIbsa, explaining $53 \%, 51 \%$ and $52 \%$ of variability respectively.

Conclusions: Our results show a deleterious effect of westernized diet pattern, red meat consumption, and high salt intake on left ventricular structure and function in hypertensive black Sub-Saharan Africans. Our findings have implications for dietary choices with respect to consumption of specific food items. Our findings emphasize the importance of dietary measures for cardiovascular disease prevention. A larger-scale prospective study is needed to confirm these findings.

Keywords: Diet; Westernized dietary pattern; Mediterranean dietary pattern; Daily sodium chloride intake; Hypertension; Left ventricular mass; Left ventricular hypertrophy; Black; Sub-saharan African 


\section{Introduction}

The associations between diet and morbidity and mortality have been widely reported in relation to diseases as diverse as cancer $[1,2]$, sterility [3-5], dementia [6], cardiovascular disease [2,7], and more recently COVID-19 [8,9], to name a few. Unhealthy diet was responsible for an estimated 1 in 5 premature deaths globally from 1990 to 2016 [10]. Yet it seems that this association between diet and health has been known for millennia. Indeed, Hippocrates of Kos, Greek doctor of the century of Pericles ( $5^{\text {th }}$ century BC), father of modern medicine and author of the oath that bears his name, recognized the central role of food in the prevention and treatment of disease. In the original version of this oath, the declaration "I will apply dietetic measures for the benefit of the sick according to my ability and judgment," precedes the declarations on drugs and surgery [11].

Cardiovascular Diseases (CVDs) constitute the leading cause of global mortality and are a major contributor to reduced quality of life [12]. Nearly $80 \%$ of global CVD deaths occur in Low and MiddleIncome Countries (LMIC) where CVD and risk factor burden are on the rise as a result of an ongoing epidemiological transition [13]. Indeed, the days when infectious diseases predominated in these countries are over. Today the Cardiovascular diseases are supplanting tropical diseases. Significant dietary changes have been noted in SubSaharan Africa (SSA) [14-16] and have been considered by some authors as one of the causes of the surge in cardiovascular disease in this part of the old world $[17,18]$. Indeed, diet has a proven impact on cardiovascular disease. A healthy diet decreases the risk of coronary artery disease, in particular by improving the blood pressure, glycemic, lipid, oxidative and inflammatory profile. An unhealthy diet, on the other hand, would promote the onset of these diseases [19-24]. Almost all of studies on the impact of specific foods, nutrients, and drinks as well as dietary patterns on cardiovascular health [25-31] have been conducted in populations in developed countries. Aside from some recent data which give some fragmentary information on some populations in developing countries [32,33] data's are almost nonexistent for these countries. Furthermore, the ideal diet for specific patients, taking into account their risk factor profile, remains a matter of controversy $[34,35]$.

In hypertensive patients, left ventricular hypertrophy (LVH) is a strong predictor of cardiovascular events including sudden death, congestive heart failure and stroke [36-38].

The purpose of this present study is to investigate the associations between daily sodium intakes, certain specific foods as well as different diet patterns (Mediterranean Diet Pattern (MDP), Westernized Diet Pattern (WDP) and Indeterminate Diet Pattern (IDP)) with left ventricular remodeling in Black Sub-Saharan African participants in Kinshasa, Democratic Republic of Congo (DRC).

\section{Material and Methods}

The present cross-sectional study involved 77 apparently healthy black Congolese hypertensive participants without a major morbid cardiovascular history. The participants were selected during outpatient consultations in the cardiology units of the University hospital of Kinshasa, the Centre Medical de Kinshasa (CMK), the General Reference Hospital of Kinshasa, the Ngaliema Clinic and the Lomo-Médical Clinic for 5 consecutive days from Tuesday, September 24, 2019, date of World Heart Day 2019.

Socio-demographic (i.e., age, sex), dietary, anthropometric, and echocardiographic data were collected for each participant. Sociodemographic and dietary data were collected by trained investigators, using a standardized questionnaire, in each of the 5 aforementioned recruiting hospitals. Anthropometric data and echocardiographic parameters were collected at the CMK during an individually negotiated appointment with each participant. The CMK is a private referral clinic working on international standards and norms. It has the best equipped cardiology unit in Central Africa, with highly qualified and regularly retrained staff.

\section{Patient selection}

All hypertensive patients aged 20 years and over who presented for an outpatient visit to the 5 aforementioned cardiology units during the study period were targeted to participate in this study. They were initially reviewed for clinical and/or paraclinical evidence of secondary hypertension, kidney and liver disease. Patients in whom no clinical or laboratory evidence of secondary hypertension, kidney or liver disease was found were selected for the study. The participants thus selected were invited, after free and informed consent, to participate in the present study. Patients with heart disease unrelated to arterial hypertension as well as those using diuretics were excluded.

\section{Study procedures}

Anamnestic data: The following information was gathered by a trained interviewer using an ad-hoc questionnaire. These are demographic data (age, sex), lifestyle data (high alcohol consumption, cigarette smoking, eating habits), medical history including cardiovascular risk factors (diabetes mellitus, dyslipidemia, hyperuricemia, menopause, duration of high blood pressure), a history of cardiovascular events (heart failure, ischemic heart disease, cardiovascular surgery, stroke, chronic kidney disease) and chronic use of certain drugs, in particular antihypertensive drugs, anti-diabetics, statins, anti-platelet drugs, hypouricemic drugs and combined contraceptives). Sedentary behavior was assessed using the World Health Organization's Global Physical Activity Questionnaire (WHO/GPAQ) [39]. Dietary behaviors were evaluated using a semi-quantitative Food Frequency Questionnaire (FFQ) [40]. The participants were interviewed on their average weekly consumption frequency of fruits, vegetables, legumes (soybeans, beans, peas, peanuts), cereals (rice, wheat, corn, sorghum), nuts, fish, dairy products and red meat.

Anthropometric data: The following anthropometric measurements were measured by a trained observer in accordance with WHO recommendations: body weight, height, and waist and hip circumference. Body mass index (BMI) was calculated as a derived variable as follows:

\section{BMI=Body weight $/$ height ${ }^{2}$}

The body surface area (BSA) was calculated using the DuBois formula [14] as follows:

$$
\text { BSA=Height }(\mathrm{cm})^{0.725} \times \text { Weight }(\mathrm{kg})^{0.425} \times 0.007184
$$

BMI was obtained by dividing the weight $(\mathrm{kg})$ by the height $(\mathrm{m})$ squared.

Blood pressure: Blood pressure was measured automatically and non-invasively by 24-hour Ambulatory Blood Pressure Monitoring (ABPM) using a TONOPORT V type recorder (GE Health care, Freiburg, GERMANY).

Echocardiographic data: A comprehensive echocardiographic assessment of left ventricular structure and function was performed for each participant as per the updated recommendations from the American Society of Echocardiography and the European Association 
of Cardiovascular Imaging [41], using a Vivid T8 type ultrasound machine (GE Health Care, Freiburg, ALLEMAGNE) equipped with a $3.5 \mathrm{MHz}$ probe.

The left ventricular dimensions (Interventricular Septum (IVS), End-Diastolic Diameter (EDD) and Posterior Wall Thickness (PWT)) were measured from a long-axis parasternal section on a twodimensional image frozen in end-diastole, at the end of the mitral leaflets. The end of the diastole was detected by a simultaneous ECG. The values of the aforementioned dimensions were used for the calculation of the LVM according to the formula, as follows: LVM $(\mathrm{g})=0.8 \times 1.04 \times\left[(\text { LVED }+ \text { IVS }+ \text { PWT })^{3}-(\text { LVED })^{3}\right]+0.6 \mathrm{~g}$.

The LVM was then indexed to the body surface area expressed in square meters and to the height expressed in meters and raised to the power of 2.7. The relative wall thickness (RWT) was calculated by the quotient of double the PWT by $\operatorname{LVED}((2 \times \mathrm{PWT}) / \mathrm{LVED})$. Mitral flow analysis was performed in a four-chamber apical section using pulsed doppler, placing the measurement volume at the end of the mitral leaflets. The $\mathrm{E}$ waves (maximum speed of the $\mathrm{E}$ wave) and $\mathrm{A}$ (maximum speed of the A wave) as well as the deceleration time of the $\mathrm{E}$ wave (TDE) were thus recorded. The average of five consecutive measurements of various aforementioned parameters was recorded. Pulsed tissue doppler echocardiography recorded mitral annular velocities from the apical window. The sample volume was placed on the lateral side of the mitral ring. The area of the left atrium was measured planimetrically on an apical four-cavity section.

Laboratory measurements: Each participant received a suitable plastic container for urine collection, type V-Monovette ${ }^{\circledast}$ (Nümbrecht, Germany) with clear instructions on handling the container and how to collect 24 -hour urine. The container and its contents (24 hour urine), were returned to the CMK medical laboratory, where the contents were mixed and the total volume recorded. From each container a quantity of $2 \mathrm{ml}$ of urine was taken and stored at $-20^{\circ} \mathrm{C}$. Urinary sodium was assessed using Roche Hitachi (Indianapolis, IN, USA), an indirect ionselective electrode to determine ion concentration.

The daily sodium chloride intake $(\mathrm{NaCl} g / 24 \mathrm{~h})$ was calculated from the daily sodium excretion using the formula [42]: $\mathrm{NaCl}(\mathrm{g} / 24 \mathrm{~h})=\mathrm{Na}$ (mmol/24h). 58.4/1000.

This is consistent with the fact that $1 \mathrm{~g}$ of $\mathrm{NaCl}=17.1 \mathrm{mEq}$ or 17.1 mmol of $\mathrm{Na}^{+}$.

\section{Operational definitions}

Lifestyle data: Cigarette smoking was defined as having smoked daily for at least 30 days prior to the date of the interview, regardless of the type or number of cigarettes smoked [43].

Binge drinking was defined as consuming at least 2 glasses of beer or its equivalent daily for at least 12 months prior to the date of the interview [44].

Moderate consumption of red wine was defined as a daily consumption of red wine not exceeding 1 large glass $(250 \mathrm{ml})$ of red wine [45].

Sedentary lifestyle has been defined as the habit of remaining seated, continuously or intermittently, for more than 7 hours a day [46].

A high consumption of a specific food was defined as an average of 4 to 7 days of weekly consumption of the considered food.

A low consumption of a specific food was defined as an average of fewer than 4 days of weekly consumption of the considered food.
Excessive sodium intake was defined as a daily intake of salt greater than or equal to $5 \mathrm{~g}$ regardless of the mode of ingestion [47].

The Mediterranean Diet Pattern (MDP) has been defined as comprising a high intake of at least four of the following: vegetables, legumes (including soybeans, beans, peas, peanuts), grains (including corn, wheat, rice, sorghum), tree nuts, fruits, fish; moderate consumption of red wine and small amounts of red meat and dairy products [48].

The Westernized Diet Pattern (WDP) has been defined as comprising a high intake of red meat and dairy products and a low intake of at least four of the following: vegetables, legumes, grains, fruits, nuts, fish [49].

The "Intermediate Diet Pattern" (IDP) was defined as a style of eating that did not meet the criteria of the two previous diet patterns.

Anthropometric parameters: Overweight was defined as BMI greater than $25 \mathrm{~kg} / \mathrm{m}^{2}$ of body surface area and less than $29.9 \mathrm{~kg} / \mathrm{m}^{2}$ body surface area [49].

Overall obesity was defined as a BMI equal to or greater than 30 $\mathrm{kg} / \mathrm{m}^{2}$ of body surface area [50]. Abdominal obesity was been defined as a waist circumference of $>102 \mathrm{~cm}$ and $>88 \mathrm{~cm}$ for men and women respectively [50].

Bioclinical data: Poor blood pressure control was defined as a mean nycthemeral systolic blood pressure greater than $130 \mathrm{mmHg}$ and/or a mean diastolic nycthemeral blood pressure greater than 80 $\mathrm{mmHg}$ [51].

Echographic data: Normal LVM was defined as $\leq 115 \mathrm{~g} / \mathrm{m}^{2}$ or $\leq$ $48 \mathrm{~g} / \mathrm{m}^{2.7}$ for males and $\leq 95 \mathrm{~g} / \mathrm{m}^{2}$ or $\leq 44 \mathrm{~g} / \mathrm{m}^{2.7}$ for females; $\mathrm{LVH}$ was defined as LVM exceeding these values in males and female patients respectively. Three patterns of diastolic dysfunction (DD) were defined as follows [52,53]: abnormal relaxation (grade I of DD: E/A ratio $<1$ and prolonged deceleration time), pseudonormal relaxation (grade II: E/A ratio $>1$ and intermediate values of deceleration time), and restrictive patterns (reversible and irreversible, grade III-IV respectively; E/A ratio $>2$ and shortened deceleration time). The dilation of the Left Atrium (LA) was defined as a LA $>20 \mathrm{~cm}^{2}$ [54].

\section{Statistical analysis}

Data are presented as number (n) and relative frequencies (\%) for categorical variables and average ( \pm standard deviation) for quantitative variables. Student's t-test was performed to compare two means. The ANOVA test was used for multiple comparisons. The ANOVA tests which proved significant at the threshold of $\mathrm{p}<0.05$ were supplemented by a post hoc Cheffée test. The influence of $\mathrm{NaCl} \mathrm{g/24}$ $\mathrm{h}$ and specific foods consumption on the left ventricular and diastolic parameters was investigated by linear regression in simple exploratory analysis respectively.

Correlation coefficients $(r)$ were calculated to determine the degree of association between left ventricular and diastolic parameters, and salt and individual foods consumption. When differences were observed between left ventricular parameters and $\mathrm{NaCl} g / 24 \mathrm{~h}$ and specific foods consumption, the effect of potential confounders including age, blood pressure, waist circumference, BMI and sedentary time was studied by adjustment in multiple linear regressions. The determination coefficients $\left(\mathrm{R}^{2}\right)$, were calculated finally to determine the degree of association between left ventricular parameters and the $\mathrm{NaCl} g / 24$ $\mathrm{h}$ and specific foods consumption. The significance threshold was $\mathrm{p}<0.05$. Statistical analyzes were performed using XLSTAT 2020 and SPSS (Statistic Package for Social Sciences) for Windows version 24 
software.

\section{Ethical Considerations}

This research was conducted in strict compliance with the recommendations of the Helsinki Declaration III. Approval to conduct the study was obtained from the ethics committee of the University of Kinshasa Public Health School prior to its commencement. All participants provided informed consent.

\section{Results}

Table 1 summarizes the general characteristics of the 77 hypertensive participants included in the final data base. The mean age of the study population was $48.7 \pm 10.4$ years with a male frequency of $52 \%$ (sex ratio $1 \mathrm{M} / 1 \mathrm{~F}$ ). The average weekly frequency of consumption of fruits, vegetables, red meat, fish and $\mathrm{NaCl} g / 24 \mathrm{~h}$ was similar in both genders ( $p>0.05$ ). In addition, we noted that the mean values of LVED, IVS, PWT, SWT and LVM were significantly higher in men than in women $(\mathrm{p}<0.05)$.

Table 2 summarizes the left ventricular parameters according to patients diet and shows that the patients on Western diet had significantly high average values of LVED, IVS, PWT, SWT, LVM, DT $(p<0.05)$, on the other hand they had significantly lower values of $\mathrm{E} / \mathrm{A}(\mathrm{p}=0.008)$. We also note that patients on western diet had a significantly high frequency of diastolic dysfunction $(\mathrm{p}=0.007)$ and of LVH $(\mathrm{p}=0.003)$.

Table 3 shows that the mean values of the LV parameters were not different between patients with normal salt intake and those with excessive salt intake $(\mathrm{p}>0.05)$.

In table 4 , shows a significant and negative linear correlation between:

- Fruit consumption per week and LVED ( $r=0.27, \mathrm{p}=0.017), \mathrm{LVM}$ $(\mathrm{r}=0.23, \mathrm{p}=0.047)$, LVMIh $(\mathrm{r}=0.28, \mathrm{p}=0.016)$, LVMIbsa $(\mathrm{r}=0.28$, $\mathrm{p}=0.015)$, DT $(\mathrm{r}=0.26, \mathrm{p}=0.023)$.

- Vegetable consumption per week and DT ( $r=0.33, \mathrm{p}=0.004)$.

- Fish consumption and LVM $(r=0.25, p=0.030)$.

And a significant and positive linear correlation between:

- Fruit consumption and $\mathrm{E} / \mathrm{A}(\mathrm{r}=0.28, \mathrm{p}=0.013)$

- Meat consumption per week and IVS ( $\mathrm{r}=0.27, \mathrm{p}=0.016)$, SWT $(\mathrm{r}=0.26, \mathrm{p}=0.013)$, LVM $(\mathrm{r}=0.32, \mathrm{p}=0.005)$, LVMIh $(\mathrm{r}=0.33$, $\mathrm{p}=0.003)$, LVMIbsa $(\mathrm{r}=0.26, \mathrm{p}=0.023)$

- Fish consumption per week and LVMIh ( $\mathrm{r}=0.36, \mathrm{p}=0.001)$

- Salt consumption per week and IVS $(r=0.29, p=0.012)$, PWT $(\mathrm{r}=0.33, \mathrm{p}=0.003)$, SWT $(\mathrm{r}=0.33, \mathrm{p}=0.004)$, LVM $(\mathrm{r}=0.34$, $\mathrm{p}=0.002)$, LVMIh $(\mathrm{r}=0.32, \mathrm{p}=0.005)$, LVMIbsa $(\mathrm{r}=0.36$, $\mathrm{p}=0.001)$, RWT $(\mathrm{r}=0.25, \mathrm{p}=0.031)$, LAA $(\mathrm{r}=0.50, \mathrm{p}<0.001)$.

In a multiple linear regression analysis (Table 5) fruits consumption, meat consumption and $\mathrm{NaCl} \mathrm{g} / 24 \mathrm{~h}$ emerged as independent determinants of LVM, LVMIh and LVMIbsa, explaining 53\%, 51\% and $52 \%$ of variability respectively.

\section{Discussion}

The present research work aimed to study the correlations between salt and specific foods consumption, as well as different dietary patterns with the left ventricular structure and function in a series of hypertensive black Sub-Saharan Africans. The study took place in Kinshasa, a crossroads of hundreds of ethnicities and cultures existing in the Democratic Republic of Congo, a country of varied foods and food habits. All the components of the studied diets (Mediterranean and Western) are widely available there, being produced locally or imported from other countries.

The present study highlighted significant favorable associations between fruit consumption, vegetable consumption and fish consumption and left ventricular structure and function parameters. The results suggest a deleterious effect of red meat, WDP and $\mathrm{NaCl}$ $\mathrm{g} / 24 \mathrm{~h}$ on the left ventricular structure and function parameters. Fruit consumption, red meat consumption and salt emerged as food independent determinants of the LVM, explaining more than $50 \%$ of its variability.

Participants on a Mediterranean diet, compared to those on a westernized diet and on intermediate diet, had a significantly lower LVM and associated measurements (IVS, PWT, LVED), with a higher $\mathrm{E} / \mathrm{A}$ and a shorter DT, suggesting a better left ventricular geometry and diastolic function.

These results agree with most previous studies, despite the great diversity of populations studied, methodologies, and operational definitions of the Mediterranean diet. Indeed, the concept of the Mediterranean diet deserves to be clarified from its historical, dietetic meaning and its operational definition. The Mediterranean diet recalls the traditional diet that prevailed in the olive growing areas of the Mediterranean basin before the mid-1960s [55]. From a dietetic point of view, it is a diet characterized by a relatively high vegetable fat intake (essentially from olive oil), which makes it palatable, low intake of saturated fat and is rich in dietary fiber. It is a diet rich in antioxidant compounds and bioactive elements with anti-inflammatory effects, and it has a low glycemic index [56]. From the point of view of the constitution of this diet, it is remarkable to note the great diversity of operational definitions reserved for it in the literature [57]. Galbete $\mathrm{C}$, et al., through a recent general review of 27 meta-analyses, listed over 30 definitions [58]. The two indices that were the most used are the one of Trichopoulou A, et al., [48] and the one of Fung TT, et al., [59]. It has recently been recommended to use one of these two definitions in order not to compromise future comparability between studies [58]. The operational definition of the MDP used in this study is adapted from that of Trichopoulou A, et al., which seems closer to the traditional Mediterranean diet.

The Mediterranean diet has been shown to be beneficial on left ventricular remodeling. Gardener $\mathrm{H}$, et al., in a multi-ethnic populationbased Northern Manhattan Study, found that greater adherence to a Mediterranean diet is associated with decreased LVM [60]. The MultiEthnic Study of Atherosclerosis (MESA) and the Northern Manhattan study showed that adherence to the Mediterranean diet improved left ventricular remodeling $[60,61]$.

The richness of this diet in antioxidant and anti-inflammatory substances, as well as its low glycemic index, provide the explanation for the favorable left ventricular profile associated with this diet. Indeed, oxidative stress, inflammation and insulin resistance are three common pathophysiological abnormalities in hypertensive patients [62-64], and play an important role in left ventricular remodeling [65]. The Mediterranean diet may, therefore, help to counter such pathophysiological anomalies.

Patients on the westernized diet had significantly greater LVM (crude and indexed to the body surface or to height) and associated measurements (IVS, PWT, LVED) compared to those of patients on the MDP and IDP. They also more often had diastolic dysfunction, with lower E/A and longer DT. These results agree with previous 
Table 1: General characteristics of the study population according to sex.

\begin{tabular}{|c|c|c|c|c|}
\hline Variables & $\begin{array}{c}\text { All } \\
n=77\end{array}$ & $\begin{array}{l}\text { Male } \\
n=40\end{array}$ & $\begin{array}{c}\text { Female } \\
n=37\end{array}$ & p-value \\
\hline Age (years) & $48.7 \pm 10.4$ & $50.2 \pm 9.7$ & $47.1 \pm 10.9$ & 0.189 \\
\hline Age groups (years) & & & & 0.139 \\
\hline$\leq \mathbf{4 0}$ & $21(27.3)$ & $7(17.5)$ & $14(37.8)$ & \\
\hline $41-50$ & $27(35.1)$ & $16(40.0)$ & $11(29.7)$ & \\
\hline$>50$ & $29(37.7)$ & $17(42.5)$ & $12(32.4)$ & \\
\hline BMI $\left(\mathrm{kg} / \mathrm{m}^{2}\right)$ & $30.5 \pm 4.7$ & $30.7 \pm 4.6$ & $30.3 \pm 4.7$ & 0.672 \\
\hline WC (Cm) & $102.9 \pm 12.1$ & $107.3 \pm 13.6$ & $98.7 \pm 8.7$ & 0.004 \\
\hline ST (hour/day) & $9.4 \pm 2.4$ & $9.1 \pm 2.2$ & $9.8 \pm 2.6$ & 0.217 \\
\hline Insulin (pmol/l) & $95.8 \pm 48.5$ & $93.2 \pm 48.8$ & $98.5 \pm 48.7$ & 0.634 \\
\hline HOMAIR & $1.9 \pm 0.9$ & $1.8 \pm 0.9$ & $2.0 \pm 1.0$ & 0.439 \\
\hline Glycemia (mmol/L) & $5.5 \pm 1.6$ & $5.7 \pm 1.6$ & $5.2 \pm 1.6$ & 0.187 \\
\hline HbA1C (\%) & $5.8 \pm 0.9$ & $6.1 \pm 0.8$ & $5.6 \pm 1.0$ & 0.021 \\
\hline \multicolumn{5}{|l|}{$\begin{array}{l}\text { Diet (days per } \\
\text { week) }\end{array}$} \\
\hline Fruits & $3.0 \pm 1.8$ & $3.0 \pm 1.8$ & $4.0 \pm 1.8$ & 0.163 \\
\hline Vegetables & $5.0 \pm 1.5$ & $5.0 \pm 1.5$ & $5.0 \pm 1.6$ & 0.694 \\
\hline Legumes & $4.0 \pm 1.4$ & $4.0 \pm 1.2$ & $4.0 \pm 1.8$ & 0.652 \\
\hline Cereals & $5.0 \pm 1.2$ & $5.0 \pm 1.4$ & $5.0 \pm 1.6$ & 0.451 \\
\hline Nuts & $2.0 \pm 1.7$ & $2.0 \pm 1.5$ & $2.0 \pm 1.8$ & 0.155 \\
\hline Fish & $4.0 \pm 1.5$ & $4.0 \pm 1.6$ & $4.0 \pm 1.4$ & 0.250 \\
\hline Red meat & $3.0 \pm 1.4$ & $4.0 \pm 1.4$ & $3.0 \pm 1.5$ & 0.311 \\
\hline Dairy products & $3.0 \pm 1.1$ & $3.0 \pm 1.2$ & $4.0 \pm 1.6$ & 0.126 \\
\hline $\mathrm{NaCl} \mathrm{g/24} \mathrm{h}$ & $12.0 \pm 8.3$ & $12.9 \pm 8.0$ & $11.1 \pm 8.6$ & 0.329 \\
\hline Insulin resistance & $18(23.4)$ & $8(20.0)$ & $10(27.0)$ & 0.592 \\
\hline Diet patterns & & & & 0.327 \\
\hline MDP & $37(48.1)$ & $16(40.0)$ & $21(56.8)$ & \\
\hline WDP & $21(27.3)$ & $13(32.5)$ & $8(21.6)$ & \\
\hline IDP & $19(24.7)$ & $11(27.5)$ & $8(21.6)$ & \\
\hline Salt intake & & & & 0.328 \\
\hline Normal & $21(27.3)$ & $9(22.5)$ & $12(32.4)$ & \\
\hline Excessive & $56(72.7)$ & $31(77.5)$ & $25(67.6)$ & \\
\hline \multicolumn{5}{|l|}{$\begin{array}{l}\text { Echocardiographic } \\
\text { parameters }\end{array}$} \\
\hline LVED (mm) & $44.4 \pm 4.3$ & $45.4 \pm 3.7$ & $43.3 \pm 4.6$ & 0.029 \\
\hline IVS (mm) & $11.5 \pm 1.8$ & $12.0 \pm 1.7$ & $10.9 \pm 1.8$ & 0.007 \\
\hline PWT (mm) & $11.5 \pm 1.7$ & $11.9 \pm 1.4$ & $10.9 \pm 1.9$ & 0.017 \\
\hline SWT (mm) & $22.9 \pm 3.3$ & $23.9 \pm 2.9$ & $21.9 \pm 3.5$ & 0.007 \\
\hline LVEF (\%) & $64.4 \pm 5.5$ & $64.1 \pm 4.5$ & 63.6 .0 & 0.125 \\
\hline LVM (g) & $184.6 \pm 44.3$ & $197.9 \pm 37.5$ & $169.8 \pm 46.9$ & 0.005 \\
\hline LVMIh $\left(\mathrm{g} / \mathrm{m}^{2.7}\right)$ & $45.8 \pm 10.7$ & $46.1 \pm 8.3$ & $45.4 \pm 13.1$ & 0.772 \\
\hline LVMIbsa $\left(\mathrm{g} / \mathrm{m}^{2}\right)$ & $92.9 \pm 20.2$ & $98.3 \pm 16.9$ & $86.9 \pm 22.0$ & 0.013 \\
\hline RWT & $0.53 \pm 0.09$ & $0.54 \pm 0.09$ & $0.51 \pm 0.10$ & 0.176 \\
\hline$E / A$ & $0.85 \pm 0.33$ & $0.80 \pm 0.27$ & $0.91 \pm 0.38$ & 0.173 \\
\hline DT (ms) & $209.1 \pm 42.0$ & $215.8 \pm 41.9$ & $201.9 \pm 41.3$ & 0.146 \\
\hline LAA $\left(\mathrm{cm}^{2}\right)$ & $16.5 \pm 4.2$ & $17.2 \pm 3.0$ & $15.8 \pm 5.1$ & 0.171 \\
\hline DD & $55(71.4)$ & $31(77.5)$ & $24(64.9)$ & 0.165 \\
\hline LVH & $35(45.5)$ & $17(42.5)$ & $18(48.6)$ & 0.377 \\
\hline LV geometry & & & & 0.291 \\
\hline Normal & $9(11.7)$ & $3(7.5)$ & $6(16.2)$ & \\
\hline $\begin{array}{l}\text { Conce n t r i c } \\
\text { remodeling }\end{array}$ & 33 (42.9) & $20(50.0)$ & $13(35.1)$ & \\
\hline Concentric LVH & $35(45.5)$ & $17(42.5)$ & $18(48.6)$ & \\
\hline
\end{tabular}

$\mathrm{BMI}=$ Body Mass Index; WC=Waist Circumference; ST=Sedentary Time; HOMAIR=Homeostatic Model Assessment for Insulin Resistance; $\mathrm{HbA} 1 \mathrm{C}=$ glycated hemoglobin; $\mathrm{NaCl} \mathrm{g} / 24 \mathrm{~h}=$ Estimated daily sodium chloride intake; MDP=Mediterranean Diet Pattern; WDP=Westernized Diet Pattern; IDP=Intermediate Diet Pattern; LVED=Left Ventricular End-
Diastolic Diameter; IVS=Interventricular Septal Thickness; PWT=Posterior Wall Thickness; SWT=Sum of Wall Thickness; LVEF=Left ventricular ejection fraction; LVM=Left Ventricular Mass; LVMIh=Left Ventricular Mass Indexed to Height ${ }^{2,7}$; LVMbs=Left Ventricular Mass Indexed to Body Surface Area; RWT=Relative Wall Thickness; $E=$ Mitral E Wave; $E / A=$ ratio of peak early and late diastolic flow velocities; DT=Deceleration Time; $\mathrm{LAA}=$ Left Atrium Area; DD=Diastolic Dysfunction; $\mathrm{LVH}=\mathrm{Left}$ Ventricular Hypertrophy; LV=Left Ventricle

Table 2: Left ventricular parameters according to diet pattern.

\begin{tabular}{|c|c|c|c|c|}
\hline Variables & $\begin{array}{l}\text { MDP } \\
n=37\end{array}$ & $\begin{array}{l}\text { WDP } \\
n=21\end{array}$ & $\begin{array}{c}\text { IDP } \\
n=19\end{array}$ & p-value \\
\hline LVED (mm) & $43.0 \pm 4.1$ & $46.5 \pm 4.3$ & $43.2 \pm 4.0$ & 0.021 \\
\hline IVS (mm) & $10.9 \pm 1.9$ & $12.4 \pm 1.8$ & $11.8 \pm 1.0$ & 0.006 \\
\hline PWT (mm) & $10.9 \pm 1.8$ & $12.1 \pm 1.5$ & $11.8 \pm 1.1$ & 0.012 \\
\hline SWT (mm) & $21.7 \pm 3.7$ & $24.5 \pm 2.9$ & $23.6 \pm 1.9$ & 0.005 \\
\hline LVM (g) & $169.9 \pm 46.5$ & $213.5 \pm 34.6$ & $180.5 \pm 32.1$ & 0.001 \\
\hline LVMIh $\left(\mathrm{g} / \mathrm{m}^{2.7}\right)$ & $42.5 \pm 12.2$ & $50.8 \pm 8.1$ & $46.6 \pm 8.3$ & 0.016 \\
\hline LVMIbsa $\left(\mathrm{g} / \mathrm{m}^{2}\right)$ & $86.4 \pm 21.9$ & $105.0 \pm 16.9$ & $92.2 \pm 14.0$ & 0.003 \\
\hline RWT & $0.50 \pm 0.09$ & $0.55 \pm 0.11$ & $0.56 \pm 0.07$ & 0.079 \\
\hline E/A & $0.97 \pm 0.36$ & $0.71 \pm 0.22$ & $0.79 \pm 0.30$ & 0.008 \\
\hline DT (ms) & $194.9 \pm 36.4$ & $233.0 \pm 39.9$ & $210.4 \pm 43.9$ & 0.003 \\
\hline LAA $\left(\mathrm{cm}^{2}\right)$ & $16.9 \pm 5.2$ & $17.0 \pm 3.1$ & $15.3 \pm 2.6$ & 0.356 \\
\hline DD & $22(59.5)$ & $20(95.2)$ & $13(68.4)$ & 0.007 \\
\hline LVH & $11(29.7)$ & $16(76.2)$ & $8(42.1)$ & 0.003 \\
\hline LV geometry & & & & 0.002 \\
\hline Normal & $8(21.6)$ & $1(4.8)$ & $0(0.0)$ & \\
\hline $\begin{array}{l}\text { Concentric } \\
\text { Remodeling } \\
\end{array}$ & $18(48.6)$ & $4(19.0)$ & $11(57.9)$ & \\
\hline Concentric LVH & $11(29.7)$ & $16(76.2)$ & $8(42.1)$ & \\
\hline
\end{tabular}

$M D P=$ Mediterranean Diet Pattern; WDP=Westernized Diet Pattern; IDP=Intermediate Diet Pattern; LVED=Left Ventricular End-Diastolic Diameter; IVS=Interventricular Septal Thickness; PWT=Posterior Wall Thickness; SWT=Sum of Wall Thickness; LVM=Left Ventricular Mass; LVMIh=Left Ventricular Mass Indexed to Height ${ }^{2,7}$; LVMbs=Left Ventricular Mass Indexed to Body Surface Area; RWT=Relative Wall Thickness; E/ $A=$ ratio of peak early and late diastolic flow velocities; $D T=$ Deceleration Time; LAA=Left Atrium Area; DD=Diastolic Dysfunction; $L V H=L e f t$ Ventricular Hypertrophy; LV=Left Ventricle

studies that have shown a significant association between the WDP and left ventricular structure and function abnormalities [66,67]. Pathophysiological disturbances related to WDP include increased production of reactive oxygen species and oxidative stress [68-70], the development of hyperinsulinemia and insulin resistance $[68,69,71]$, low-grade inflammation $[72,73]$ sympathetic nervous system [74] and renin-angiotensin-aldosterone system hyperstimulation [75]. All of these mechanisms are thought to be involved in the development of cardiovascular disease in general and LVH and diastolic dysfunction in particular [76-82].

Regarding salt consumption, there was no significant difference in left ventricular structural and functional parameters between patients with excessive salt intake and those without. However, $\mathrm{NaCl}$ $\mathrm{g} / 24 \mathrm{~h}$ is significantly positively correlated with LVM and associated measurements (IVS, PWT, LVED), as well as with LAA. In addition, $\mathrm{NaCl} g / 24 \mathrm{~h}$ has emerged as an independent determinant of LVM. This finding from our study is in accordance with studies that showed that high salt intake plays a role in the development of LVH independently

Citation: Bernard KP, Aliocha NN, Roger KZ, Annie NT, Emmanuel LB, et al. (2021) Deleterious Effect of Westernized Diet Pattern, Red Meat and High Salt Intake on Left Ventricular Structure and Function in Hypertensive Black Sub-Saharan Africans: A Multicentric Cross Sectional Study. J 
Table 3: Left ventricular parameters according to salt consumption.

\begin{tabular}{|c|c|c|c|}
\hline Variables & $\begin{array}{c}\text { Normal salt intake } \\
n=21\end{array}$ & $\begin{array}{c}\text { Excessive salt intake } \\
n=56\end{array}$ & p-value \\
\hline LVED (mm) & $44.0 \pm 3.3$ & $44.5 \pm 4.6$ & 0.614 \\
\hline IVS (mm) & $11.1 \pm 1.9$ & $11.6 \pm 1.7$ & 0.287 \\
\hline PWT (mm) & $11.1 \pm 1.9$ & $11.6 \pm 1.6$ & 0.130 \\
\hline SWT (mm) & $22.1 \pm 3.6$ & $23.3 \pm 3.2$ & 0.176 \\
\hline LVM (g) & $174.2 \pm 47.4$ & $188.6 \pm 42.8$ & 0.208 \\
\hline LVMIh $\left(\mathrm{g} / \mathrm{m}^{2.7}\right)$ & $43.2 \pm 10.7$ & $46.8 \pm 10.6$ & 0.187 \\
\hline LVMIbsa $\left(\mathrm{g} / \mathrm{m}^{2}\right)$ & $88.4 \pm 22.4$ & $94.5 \pm 19.3$ & 0.242 \\
\hline RWT & $0.50 \pm 0.08$ & $0.54 \pm 0.10$ & 0.069 \\
\hline E/A & $0.82 \pm 0.38$ & $0.86 \pm 0.31$ & 0.650 \\
\hline DT (ms) & $205.3 \pm 32.9$ & $210.6 \pm 45.1$ & 0.627 \\
\hline LAA $\left(\mathrm{cm}^{2}\right)$ & $15.6 \pm 2.6$ & $16.9 \pm 4.6$ & 0.250 \\
\hline DD & $17(81.0)$ & $38(67.9)$ & 0.200 \\
\hline LVH & $9(42.9)$ & $26(46.4)$ & 0.492 \\
\hline LV geometry & & & 0.483 \\
\hline Normal & $4(19.0)$ & $5(8.9)$ & \\
\hline $\begin{array}{l}\text { Concentric } \\
\text { remodeling }\end{array}$ & $8(38.1)$ & $25(44.6)$ & \\
\hline Concentric LVH & $9(42.9)$ & $26(46.4)$ & \\
\hline
\end{tabular}

LVED=Left Ventricular End-Diastolic Diameter; IVS=Interventricular Septal Thickness; PWT=Posterior Wall Thickness; SWT=Sum of Wall Thickness; LVM=Left Ventricular Mass; LVMIh=Left Ventricular Mass Indexed to Height ${ }^{2,7}$; LVMbs=Left Ventricula Mass Indexed to Body Surface

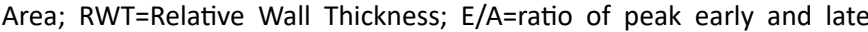
diastolic flow velocities; DT=Deceleration Time; LAA=Left Atrium Area; DD=Diastolic Dysfunction; DD=Diastolic Dysfunction; LVH=Left Ventricular Hypertrophy; LV=Left Ventricle

or in addition to its effect on BP in human [83-86] and in animals [87]. Likewise, reduction of sodium intake showed positive results in terms of decreasing LVM $[88,89]$. There are some experimental studies that shed light on our understanding of the pathophysiological mechanisms explaining this relationship; for example, activation of local RAS leading to both myocardial hypertrophy and fibrosis $[90,91]$ has been reported extensively in the literature. Chang RL, et al., have recently demonstrated the crucial role of IGF-IIR $\alpha$ (insulin-like growth factor-II receptor alternative spliced transcript) in enhancing cardiac hypertrophy under high-salt conditions [92] and Lang $\mathrm{H}$, et al., recently demonstrated a role for the Uncoupling Protein 3 (UCP3) in this process too [93]. Old theories evoking the stimulation of the sympathetic system, hemodynamic changes (pressure and volume overload), enhanced protein synthesis and increased myocardial sodium influx have not been confirmed by experimental studies [94]; however, a large community-based experiment did find that urinary sodium excretion was not related to LVM [95]. In this study, urinary sodium excretion was measured from spot urine samples. Our study used analysis of sodium excretion in 24-hour urine, which is the gold standard for measuring salt intake [96]. The rationale for using 24-hour urine as a means of assessing daily sodium intake is that the kidney regulates the body's sodium balance, which implies that the sodium that is eliminated in the urine is equivalent to food ingestants (minus a negligible amount that is eliminated in the stool or sweat, about $7 \%$ of dietary sodium). This remains true in patients undergoing long-term treatment with a diuretic, if the dose of diuretic has not been changed recently [96]. Even if spot urine samples are considered an appropriate alternative for monitoring sodium intake, they are affected by the chronobiology of sodium excretion [82], and this methodological difference could explain the discordance with our findings. The differences in the ethnic makeup of the surveyed patients could also account for these discrepancies, given observed interethnic differences in salt sensitivity $[97,98]$.

The present study has shown a significant negative correlation of fruit and fish consumption with LVM. In addition, a significant negative correlation has been found between fruit and vegetable consumption and DT. Fruit consumption was also positively correlated with E/A. Almost no studies have been conducted on the link between the consumption of fruits, vegetables, and fish as single foods and $\mathrm{LVH}$. This is due to current recommendations that encourage dietary or food group studies rather than singular food studies, suggesting that analysis of the food model evaluating the overall quality of food is easier to translate into dietary recommendations than recommendations for single foods or nutrients $[40,99]$. This approach is reasonable but perhaps questionable, as it is clearly important to acknowledge unique aspects of foods and food components that may affect disease risk independent of the overall diet [100]. Focusing on isolated nutrients certainly cannot account for all interactions and may result in erroneous conclusions [101], but research focusing on single foods items could improve mechanistic understanding of the effects of diet patterns [100]. In a previous biracial population based study, we found that reduced fruit consumption was independently and significantly associated with echocardiographic LVH [102]. Studies have shown an inverse association between fruit consumption and the risk of cardiovascular events $[25,103]$. The cardioprotective mechanisms of fruits remain unclear, but their exceptional antioxidant and free radical scavenging properties are considered to be important in conferring protection [104]. These same properties could be the underlying mechanism of this inverse relationship between fruit consumption and $\mathrm{LVH}$ as it has been shown that oxidative stress plays a role in the genesis of $\mathrm{LVH}[65,105]$.

In this study, significant consumption of meat was found to be significantly positively correlated with LVM and associated measurements (IVS, PWT, LVED). A study performed by Haring $\mathrm{B}$, et al., is one of few (if not the only example) that examined the relationship between the consumption of red meat as an individual food and the LVM. This study found no correlation between processed and unprocessed red meat consumption and LVM in American Indians [106]. This contradiction with the findings of our study could possibly be explained by race-related genetic factors that could confound the association between meat consumption and LVM. Another explanation for this contradiction might come from the fact that dietary intake was determined using FFQs, and some participants may not have adequately recalled dietary information on specific foods (recall bias). This bias may have reduced the observed associations, potentially causing an underestimation of true associations.

\section{Study Strengths and Limitations}

This study has strengths and limitations that should be noted. To our knowledge, this is the first study that has evaluated the implications of diet on left ventricular hypertrophy in hypertensive black Sub-Saharan Africans. The multicentric design and standardized echocardiographic measurements performed are also particular strengths of our study. Although echocardiographic measurements can be prone to errors due to signal noise, acoustic artifacts, and angle dependency, in the 
Table 4: Correlation between ultrasound parameters and diet.

\begin{tabular}{|c|c|c|c|c|c|}
\hline Variables & $\begin{array}{l}\text { Fruit consumption } \\
\qquad r \text { ( } p \text {-value) }\end{array}$ & $\begin{array}{c}\text { Vegetable consumption } \\
\text { r (p-value) }\end{array}$ & $\begin{array}{l}\text { Fish consumption } \\
\qquad r \text { ( } p \text {-value) }\end{array}$ & $\begin{array}{c}\text { Meat consumption } \\
r \text { (p-value) }\end{array}$ & $\begin{array}{l}\text { Sal intake } \\
r \text { (p-value) }\end{array}$ \\
\hline LVED (mm) & $-0.27(\mathbf{0 . 0 1 7})$ & $-0.08(0.498)$ & $-0.19(0.105)$ & $0.21(0.064)$ & $0.18(0.114)$ \\
\hline IVS (mm) & $-0.11(0.335)$ & $-0.07(0.550)$ & $-0.24(\mathbf{0 . 0 3 3})^{*}$ & $0.27(0.016)^{*}$ & $0.29(0.012)^{*}$ \\
\hline PWT (mm) & $-0.17(0.152)$ & $0.04(0.726)$ & $-0.15(0.189)$ & $0.22(0.060)$ & $0.33(0.003)$ \\
\hline SWT (mm) & $-0.15(0.210)$ & $-0.02(0.882)$ & $-0.21(0.067)$ & $0.26(0.023)$ & $0.33(0.004)^{*}$ \\
\hline LVM (g) & $-0.23(0.047)$ & $-0.05(0.653)$ & $-0.25(0.030)$ & $0.32(0.005)$ & $0.34(0.002)^{*}$ \\
\hline LVMIh $\left(\mathrm{g} / \mathrm{m}^{2.7}\right)$ & $-0.28(0.016)$ & $-0.07(0.538)$ & $0.36(0.001)$ & $0.33(0.003)$ & $0.32(0.005)$ \\
\hline LVMIbsa $\left(\mathrm{g} / \mathrm{m}^{2}\right)$ & $-0.28(0.015)$ & $-0.06(0.585)$ & $-0.22(0.050)$ & $0.26(0.023)$ & $0.36(0.001)$ \\
\hline RWT & $-0.05(0.698)$ & $0.03(0.769)$ & $-0.07(0.521)$ & $0.13(0.265)$ & $0.25(0.031)$ \\
\hline E/A & $0.28(0.013)$ & $0.20(0.085)$ & $0.18(0.118)$ & $-0.15(0.204)$ & $0.02(0.868)$ \\
\hline DT (ms) & $-0.26(0.023)^{*}$ & $-0.33(0.004)$ & $-0.20(0.075)$ & $0.17(0.135)$ & $0.17(0.142)$ \\
\hline LAA $\left(\mathrm{cm}^{2}\right)$ & $-0.10(0.382)$ & $0.07(0.521)$ & $-0.04(0.758)$ & $0.02(0.851)$ & $0.50(<0.001)$ \\
\hline
\end{tabular}

LVED=Left Ventricular End-Diastolic Diameter; IVS=Interventricular Septal Thickness; PWT=Posterior Wall Thickness; SWT=Sum of Wall Thickness; LVM=Left Ventricular Mass; LVMIh=Left Ventricular Mass Indexed to Height ${ }^{2,7}$; LVMbs=Left Ventricular Mass Indexed to Body Surface Area; RWT=Relative Wall Thickness; $E / A=$ ratio of peak early and late diastolic flow velocities; DT=Deceleration Time; LAA=Left Atrium Area

Table 5: Dietary determinants of left ventricular mass.

\begin{tabular}{|c|c|c|c|c|c|c|c|c|c|}
\hline \multirow{2}{*}{ Variables } & \multicolumn{3}{|c|}{ LVM } & \multicolumn{3}{|c|}{ LVMIh } & \multicolumn{3}{|c|}{ LVMIbsa } \\
\hline & $\beta$ & ES & $\mathbf{P}$ & $\beta$ & ES & p & $\beta$ & ES & p \\
\hline Constant & 158.343 & 24.642 & 0.000 & 35.472 & 6.057 & 0.000 & 86.027 & 11.374 & 0.000 \\
\hline Fruits consumption & -3.880 & 2.731 & 0.016 & -1.299 & 0.671 & 0.017 & -2.310 & 1.255 & 0.010 \\
\hline Vegetables consumption & 1.975 & 3.237 & 0.544 & 0.235 & 0.796 & 0.769 & 0.799 & 1.494 & 0.594 \\
\hline Red meat consumption & 8.150 & 3.399 & 0.019 & 2.508 & 0.836 & 0.004 & 2.729 & 1.565 & 0.015 \\
\hline Fish consumption & -5.350 & 3.289 & 0.108 & 0.067 & 0.808 & 0.934 & -2.329 & 1.517 & 0.129 \\
\hline \multirow[t]{2}{*}{$\mathrm{NaCl}$ g/24 h } & 1.837 & 0.550 & 0.001 & 0.385 & 0.135 & 0.006 & 0.853 & 0.254 & 0.001 \\
\hline & \multicolumn{3}{|c|}{$R^{2}=0.53$} & \multicolumn{3}{|c|}{$R^{2}=0.512$} & \multicolumn{3}{|c|}{$R^{2}=0.516$} \\
\hline Overall p-value & \multicolumn{3}{|c|}{$<0.001$} & \multicolumn{3}{|c|}{0.001} & \multicolumn{3}{|c|}{$<0.001$} \\
\hline
\end{tabular}

LVM=Left Ventricular Mass; LVMIh=Left Ventricular Mass Indexed to Height; LVMIbsa=Left Ventricular Mass Indexed to Body Surface Area; NaCl g/24 $\mathrm{h}=$ Estimated daily sodium chloride intake

present study, echocardiography was performed by an experienced cardiologist with post-graduate training in cardiac imaging. In this study, dietary behaviors were evaluated using a semi-quantitative Food Frequency Questionnaire (FFQ). This is a method widely used in epidemiology to assess the eating habits of respondents [40]. The FFQ used in the present study has a double limitation. First, this questionnaire explored the frequency rather than the actual amount of different foods consumed, assuming that frequency of consumption is a surrogate for quantity. Second, this questionnaire is based on the memory and skills of the interviewer. However, using the previous week as a reference period could reduce reporting biases due to memory. Finally, the cross-sectional design of this study does not allow formal establishment of any causal links in the observed associations, and the existence of potential confounding factors remains possible.

\section{Conclusions}

Our results showed a deleterious effect of westernized diet pattern, red meat consumption and high salt intake on left ventricular structure and function in hypertensive black Sub-Saharan Africans. Our findings have implications for dietary choices with respect to consumption of specific food items. Our data support current international hypertension guidelines [107-109] and lifestyle management guidelines that recommend limiting red meat consumption and encourage the consumption of fruits, vegetables and fish as one step towards maintaining and promoting cardiovascular health $[110,111]$.

\section{Author's Contributions}

Design and concept of study: Kianu Phanzu Bernard

Acquisition of data: Kianu Phanzu Bernard, Kokusa Zamani Roger, Nzundu Tufuankenda Annie, Limbole Baliko Emmanuel

Manuscript draft: Kianu Phanzu Bernard

Supervision: Kintoki Vita Eleuthère, Longo-Mbenza Benjamin, M’Buyamba-Kabangu Jean-René

Statistical analysis: Nkodila Natuhoyila Aliocha

All authors read and approved the final manuscript.

\section{References}

1. Bertuccio P, Rosato V, Andreano A, Ferraroni M, Decarli A, et al. (2013) Dietary patterns and gastric cancer risk: a systematic review and meta-analysis. Ann Oncol 24: 1450-1458. 
2. Takachi R, Inoue M, Ishihara J, Kurahashi N, Iwasaki M, et al. (2008) Fruit and vegetable intake and risk of total cancer and cardiovascular disease: Japan Public Health Center-Based Prospective Study. Am J Epidemiol 167: 59-70.

3. Toledo E, Lopez-del Burgo C, Ruiz-Zambrana A, Donazar M, NavarroBlasco I, et al. (2011) Dietary patterns and difficulty conceiving: a nested case-control study. Fertil Steril 96: 1149-1153.

4. Nazni P (2014) Association of western diet \& lifestyle with decreased fertility. Indian J Med Res 140: S78-S81.

5. Nassan FL, Chavarro JE, Tanrikut C (2018) Diet and men's fertility: does diet affect sperm quality? Fertil Steril 110: 570-577.

6. Akbaraly TN, Singh-Manoux A, Dugravot A, Brunner EJ, Kivimaki M, et al. (2019) Association of Midlife Diet With Subsequent Risk for Dementia. JAMA 321: 957-968.

7. Nagura J, Iso H, Watanabe Y, Maruyama K, Date C, et al. (2009) Fruit, vegetable and bean intake and mortality from cardiovascular disease among Japanese men and women: the JACC Study. Br J Nutr 102: $285-292$

8. Kalantar-Zadeh K, Moore LW (2020) Impact of Nutrition and Diet on COVID-19 Infection and Implications for Kidney Health and Kidney Disease Management. J Ren Nutr 30: 179-181.

9. Messina G, Polito R, Monda V, Cipolloni L, Di Nunno N, et al. (2020) Functional Role of Dietary Intervention to Improve the Outcome of COVID-19: A Hypothesis of Work. Int J Mol Sci 21: 3104.

10. GBD 2016 Risk Factors Collaborators (2017) Global, regional, and national comparative risk assessment of 84 behavioural, environmental and occupational, and metabolic risks or clusters of risks, 1990-2016: a systematic analysis for the Global Burden of Disease Study 2016. Lancet 390: 1345-1422.

11. Hasday LR (2002) The Hippocratic oath as literary text: a dialogue between law and medicine. Yale J Health Policy Law Ethics 2: 299 323.

12. GBD 2017 Risk Factors Collaborators (2018) Global, regional, and national age-sex-specific mortality for 282 causes of death in 195 countries and territories, 1980-2017: a systematic analysis for the Global Burden of Disease Study 2017. Lancet 392: P1736-P1788.

13. Fuster V (2014) Global burden of cardiovascular disease: time to implement feasible strategies and to monitor results. J Am Coll Cardiol 64: 520-522.

14. Monteiro CA, Moubarac JC, Cannon G, Ng SW, Popkin B (2013) Ultra-processed products are becoming dominant in the global food system. Obes Rev 14: 21-28.

15. Steyn NP, McHiza ZJ (2014) Obesity and the nutrition transition in Sub-Saharan Africa. Ann N Y Acad Sci 1311: 88-101.

16. Misselhorn A, Hendriks SL (2017) A systematic review of sub-national food insecurity research in South Africa: Missed opportunities for policy insights. PLoS One 12: e0182399.

17. Amegah AK (2018) Tackling the Growing Burden of Cardiovascular Diseases in Sub-Saharan Africa. Circulation 138: 2449-2451.

18. Haggblade S, Duodu KG, Kabasa JD, Minnaar A, Ojijo NKO, et al. (2016) Emerging Early Actions to Bend the Curve in Sub-Saharan Africa's Nutrition Transition. Food Nutr Bull 37: 219-241.

19. Busnelli M, Manzini S, Sirtori CR, Chiesa G, Parolini C (2018) Effects of Vegetable Proteins on Hypercholesterolemia and Gut Microbiota Modulation. Nutrients 10: 1249.
20. Sanchez A, Mejia A, Sanchez J, Runte E, Brown-Fraser S, et al. (2019) Diets with customary levels of fat from plant origin may reverse coronary artery disease. Med Hypotheses 122: 103-105.

21. Ozemek C, Laddu DR, Arena R, Lavie CJ (2018) The role of diet for prevention and management of hypertension. Curr Opin Cardiol 33: 388-393.

22. Tosti V, Bertozzi B, Fontana L (2018) Health Benefits of the Mediterranean Diet: Metabolic and Molecular Mechanisms. Gerontol A Biol Sci Med Sci 73: 318-326.

23. Gjuladin-Hellon T, Davies IG, Penson P, Amiri Baghbadorani R (2019) Effects of carbohydrate-restricted diets on low-density lipoprotein cholesterol levels in overweight and obese adults: a systematic review and meta-analysis. Nutr Rev 77: 161-180.

24. Feinman RD, Pogozelski WK, Astrup A, Bernstein RK, Fine EJ, et al. (2015) Dietary carbohydrate restriction as the first approach in diabetes management: critical review and evidence base. Nutrition 31: 1-13.

25. Aune D, Giovannucci E, Boffetta P, Fadnes LT, Keum N, et al. (2017) Fruit and vegetable intake and the risk of cardiovascular disease, total cancer and all-cause mortality-a systematic review and doseresponse meta-analysis of prospective studies. Int J Epidemiol 46 : 1029-1056.

26. Borch $D$, Juul-Hindsgaul $N$, Veller $M$, Astrup A, Jaskolowski J, et al. (2016) Potatoes and risk of obesity, type 2 diabetes, and cardiovascular disease in apparently healthy adults: a systematic review of clinical intervention and observational studies. Am J Clin Nutr 104: 489-498.

27. Ebbeling CB, Swain JF, Feldman HA, Wong WW, Hachey DL, et al. (2012) Effects of dietary composition on energy expenditure during weight-loss maintenance. JAMA 307: 2627-2634.

28. Casas R, Castro-Barquero S, Estruch R, Sacanella E (2018) Nutrition and Cardiovascular Health. Int J Mol Sci 19: 3988.

29. Brandhorst S, Longo VD (2019) Dietary Restrictions and Nutrition in the Prevention and Treatment of Cardiovascular Disease. Circ Res 124: $952-965$

30. Tapsell LC, Neale EP, Probst Y (2019) Dietary Patterns and Cardiovascular Disease: Insights and Challenges for Considering Food Groups and Nutrient Sources. Curr Atheroscler Rep 21: 9.

31. Suliga E, Koziel D, Ciesla E, Rebak D, Gluszek-Osuch M, et al. (2019) The Consumption of Alcoholic Beverages and the Prevalence of Cardiovascular Diseases in Men and Women: A Cross-Sectional Study. Nutrients 11: 1318.

32. Imamura F, Micha R, Khatibzadeh S, Fahimi S, Shi P, et al. (2015) Dietary quality among men and women in 187 countries in 1990 and 2010: a systematic assessment. Lancet Glob Health 3: e132-e142.

33. Micha R, Khatibzadeh S, Shi P, Fahimi S, Lim S, et al. (2014) Global, regional, and national consumption levels of dietary fats and oils in 1990 and 2010: a systematic analysis including 266 country-specific nutrition surveys. BMJ 348: g2272.

34. Hruby A, Jacques PF (2018) Dietary protein and changes in markers of cardiometabolic health across 20 years of follow-up in middleaged Americans. Public Health Nutr 21: 2998-3010.

35. Haring B, Gronroos N, Nettleton JA, von Ballmoos MCW, Selvin E, et al. (2014) Dietary protein intake and coronary heart disease in a large community based cohort: results from the Atherosclerosis Risk in Communities (ARIC) study [corrected]. PLoS One 9: e109552. 
36. Barsukov AV, Glukhovskoi DV, Zobnina MP, Mirokhina MA, Dydyshko VT, et al. (2014) Left ventricular hypertrophy as a marker of adverse cardiovascular risk in persons of various age groups. Adv Gerontol 27: 763-770

37. Stewart MH, Lavie CJ, Shah S, Englert J, Gilliland Y, et al. (2018) Prognostic Implications of Left Ventricular Hypertrophy. Prog Cardiovasc Dis 61: 446-455.

38. Yildiz M, Oktay AA, Stewart MH, Milani RV, Ventura HO, et al. (2020) Left ventricular hypertrophy and hypertension. Prog Cardiovasc Dis 63: 10-21.

39. Cleland CL, Hunter RF, Kee F, Cupples ME, Sallis JF, et al. (2014) Validity of the global physical activity questionnaire (GPAQ) in assessing levels and change in moderate-vigorous physical activity and sedentary behaviour. BMC Public Health 14: 1255.

40. Shim JS, Oh K, Kim HC (2014) Dietary assessment methods in epidemiologic studies. Epidemiol Health 36: e2014009.

41. Lang RM, Badano LP, Mor-Avi V, Afilalo J, Armstrong A, et al. (2015) Recommendations for cardiac chamber quantification by echocardiography in adults: an update from the American Society of Echocardiography and the European Association of Cardiovascular Imaging. J Am Soc Echocardiogr 28: 1-39.e14.

42. Huang L, Crino M, Wu JH, Woodward M, Barzi F, et al. (2016) Mean population salt intake estimated from 24-h urine samples and spot urine samples: a systematic review and meta-analysis. Int $J$ Epidemiol 45: 239-250.

43. Ryan H, Trosclair A, Gfroerer J (2012) Adult current smoking: differences in definitions and prevalence estimates--NHIS and NSDUH, 2008. J Environ Public Health 2012: 918368.

44. Moos RH, Schutte KK, Brennan PL, Moos BS (2009) Older adults' alcohol consumption and late-life drinking problems: a 20-year perspective. Addiction 104: 1293-1302.

45. Chiva-Blanch G, Urpi-Sarda M, Ros E, Valderas-Martinez P, Casas R, et al. (2013) Effects of red wine polyphenols and alcohol on glucose metabolism and the lipid profile: a randomized clinical trial. Clin Nutr 32: 200-206.

46. Ku PW, Steptoe A, Liao Y, Hsueh MC, Chen LJ (2018) A cut-off of daily sedentary time and all-cause mortality in adults: a meta-regression analysis involving more than 1 million participants. BMC Med 16: 74

47. Campbell NR, Correa-Rotter R, Cappuccio FP, Webster J, Lackland DT, et al. (2015) Proposed nomenclature for salt intake and for reductions in dietary salt. J Clin Hypertens (Greenwich) 17: 247-251.

48. Trichopoulou A, Costacou T, Bamia C, Trichopoulos D (2003) Adherence to a Mediterranean diet and survival in a Greek population. N Engl J Med 348: 2599-2608.

49. Maugeri A, Hruskova J, Jakubik J, Hlinomaz O, Medina-Inojosa JR, et al. (2019) How dietary patterns affect left ventricular structure, function and remodelling: evidence from the Kardiovize Brno 2030 study. Sci Rep 9: 19154

50. GBD 2015 Obesity Collaborators, Afshin A, Forouzanfar MH, Reitsma $M B$, Sur P, et al. (2017) Health Effects of Overweight and Obesity in 195 Countries over 25 Years. N Engl J Med 377: 13-27.

51. Whelton PK, Carey RM, Aronow WS, Casey DE Jr, Collins KJ, et al. (2018) 2017 ACC/AHA/AAPA/ABC/ACPM/AGS/APhA/ASH/ASPC/ NMA/PCNA Guideline for the Prevention, Detection, Evaluation, and Management of High Blood Pressure in Adults: A Report of the American College of Cardiology/American Heart Association Task Force on Clinical Practice Guidelines. Hypertension 71: e13-e115.
52. Galderisi M, Cosyns B, Edvardsen T, Cardim N, Delgado V, et al. (2017) Standardization of adult transthoracic echocardiography reporting in agreement with recent chamber quantification, diastolic function, and heart valve disease recommendations: an expert consensus document of the European Association of Cardiovascular Imaging. Eur Heart J Cardiovasc Imaging 18: 1301-1310.

53. Nagueh SF (2020) Left Ventricular Diastolic Function: Understanding Pathophysiology, Diagnosis, and Prognosis with Echocardiography. JACC Cardiovasc Imaging 13: 228-244.

54. Lang RM, Badano LP, Mor-Avi V, Afilalo J, Armstrong A, et al (2015) Recommendations for cardiac chamber quantification by echocardiography in adults: an update from the American Society of Echocardiography and the European Association of Cardiovascular Imaging. Eur Heart J Cardiovasc Imaging 16: 233-270.

55. Trichopoulou A, Martinez-Gonzalez MA, Tong TYN, Forouhi NG, Khandelwal S, et al. (2014) Definitions and potential health benefits of the Mediterranean diet: views from experts around the world. BMC Med 12: 112

56. Roman-Vinas B, Ribas Barba L, Ngo J, Martinez-Gonzalez MA, Wijnhoven TMA, et al. (2009) Validity of dietary patterns to assess nutrient intake adequacy. Br J Nutr 101: S12-S20.

57. Huedo-Medina TB, Garcia M, Bihuniak JD, Kenny A, Kerstetter J (2016) Methodologic quality of meta-analyses and systematic reviews on the Mediterranean diet and cardiovascular disease outcomes: a review. Am J Clin Nutr 103: 841-850.

58. Galbete C, Schwingshackl L, Schwedhelm C, Boeing H, Schulze MB (2018) Evaluating Mediterranean diet and risk of chronic disease in cohort studies: an umbrella review of meta-analyses. Eur J Epidemiol 33: 909-931.

59. Fung TT, Rexrode KM, Mantzoros CS, Manson JE, Willett WC, et al (2009) Mediterranean diet and incidence of and mortality from coronary heart disease and stroke in women. Circulation 119: 1093100

60. Gardener H, Rundek T, Wright CB, Gu Y, Scarmeas N, et al. (2015) A Mediterranean-style diet and left ventricular mass (from the Northern Manhattan Study). Am J Cardiol 115: 510-514.

61. Levitan EB, Ahmed A, Arnett DK, Polak JF, Hundley WG, et al. (2016) Mediterranean diet score and left ventricular structure and function: the Multi-Ethnic Study of Atherosclerosis. Am J Clin Nutr 104: 595-602.

62. Gonzalez J, Valls N, Brito R, Rodrigo R (2014) Essential hypertension and oxidative stress: New insights. World J Cardiol 6: 353-366.

63. McCarthy CG, Goulopoulou S, Webb RC (2019) Paying the Toll for Inflammation: Immunoreceptor-Mediated Vascular Dysfunction in Hypertension. Hypertension 73: 514-521.

64. Ormazabal V, Nair S, Elfeky O, Aguayo C, Salomon C, et al. (2018) Association between insulin resistance and the development of cardiovascular disease. Cardiovasc Diabetol 17: 122.

65. Rababa'h AM, Guillory AN, Mustafa R, Hijjawi T (2018) Oxidative Stress and Cardiac Remodeling: An Updated Edge. Curr Cardiol Rev 14: 53-59.

66. Ferron AJT, Francisqueti FV, Minatel IO, Silva CCVA, Bazan SGZ, et al. (2018) Association between Cardiac Remodeling and Metabolic Alteration in an Experimental Model of Obesity Induced by Western Diet. Nutrients 10: 1675

67. Behring JB, Kumar V, Whelan SA, Chauhan P, Siwik DA, et al. (2014) Does reversible cysteine oxidation link the Western diet to cardiac dysfunction? FASEB J 28: 1975-1987. 
68. Tan BL, Norhaizan ME, Liew WP (2018) Nutrients and Oxidative Stress: Friend or Foe? Oxid Med Cell Longev 2018: 9719584

69. Sies H, Stahl W, Sevanian A (2005) Nutritional, dietary and postprandial oxidative stress. J Nutr 135: 969-972.

70. Erdelyi I, Levenkova N, Lin EY, Pinto JT, Lipkin M, et al. (2009) Western-style diets induce oxidative stress and dysregulate immune responses in the colon in a mouse model of sporadic colon cancer. $J$ Nutr 139: 2072-2078.

71. Heinonen I, Rinne P, Ruohonen ST, Ruohonen S, Ahotupa $M$, et al. (2014) The effects of equal caloric high fat and western diet on metabolic syndrome, oxidative stress and vascular endothelial function in mice. Acta Physiol (Oxf) 211: 515-527.

72. Simopoulos AP (2016) An Increase in the Omega-6/Omega-3 Fatty Acid Ratio Increases the Risk for Obesity. Nutrients 8: 128.

73. Christ A, Gunther P, Lauterbach MAR, Duewell P, Biswas D, et al. (2018) Western Diet Triggers NLRP3-Dependent Innate Immune Reprogramming. Cell 172: 162-175.e14.

74. Lambert GW, Schlaich MP, Eikelis N, Lambert EA (2019) Sympathetic activity in obesity: a brief review of methods and supportive data. Ann N Y Acad Sci 1454: 56-67.

75. Jin N, Wang Y, Liu L, Xue F, Jiang T, et al. (2019) Dysregulation of the Renin-Angiotensin System and Cardiometabolic Status in Mice Fed a Long-Term High-Fat Diet. Med Sci Monit 25: 6605-6614.

76. Sverdlov AL, Elezaby A, Qin F, Behring JB, Luptak I, et al. (2016) Mitochondrial Reactive Oxygen Species Mediate Cardiac Structural, Functional, and Mitochondrial Consequences of Diet-Induced Metabolic Heart Disease. J Am Heart Assoc 5: e002555.

77. Cauwenberghs N, Knez J, Thijs L, Haddad F, Vanassche T, et al. (2018) Relation of Insulin Resistance to Longitudinal Changes in Left Ventricular Structure and Function in a General Population. J Am Heart Assoc 7: e008315.

78. Oncel CR (2016) Left ventricular hypertrophy, inflammation, and insulin resistance. Anatol J Cardiol 16: 142.

79. Ozel E, Tastan A, Ozturk A, Ozcan EE (2015) Relationship between Sympathetic Overactivity and Left Ventricular Hypertrophy in Resistant Hypertension. Hellenic J Cardiol 56: 501-506.

80. Fan Z, Wu G, Yue M, Ye J, Chen Y, et al. (2019) Hypertension and hypertensive left ventricular hypertrophy are associated with ACE2 genetic polymorphism. Life Sci 225: 39-45.

81. Jeckel KM, Veeramachaneni DN, Chicco AJ, Chapman PL, Mulligan CM, et al. (2012) Docosahexaenoic acid supplementation does not improve Western diet-induced cardiomyopathy in rats. PLoS One 7: e51994.

82. Zeng H, Vaka VR, He X, Booz GW, Chen JX (2015) High-fat diet induces cardiac remodelling and dysfunction: assessment of the role played by SIRT3 loss. J Cell Mol Med 19: 1847-1856.

83. Du Cailar G, Ribstein J, Daures JP, Mimran A (1992) Sodium and left ventricular mass in untreated hypertensive and normotensive subjects. Am J Physiol 263: H177-H181.

84. Schmieder RE, Messerli FH, Garavaglia GE, Nunez BD (1988) Dietary salt intake. A determinant of cardiac involvement in essential hypertension. Circulation 78: 951-956.

85. du Cailar G, Ribstein J, Mimran A (2002) Dietary sodium and target organ damage in essential hypertension. Am J Hypertens 15: 222229.
86. Kupari M, Koskinen P, Virolainen J (1994) Correlates of left ventricular mass in a population sample aged 36 to 37 years. Focus on lifestyle and salt intake. Circulation 89: 1041-1050.

87. Yuan BX, Leenen FH (1991) Dietary sodium intake and left ventricular hypertrophy in normotensive rats. Am J Physiol 261: H1397-H1401.

88. van der Westhuizen B, Schutte AE, Gafane-Matemane LF, Kruger R (2019) Left ventricular mass independently associates with 24-hour sodium excretion in young masked hypertensive adults: The AfricanPREDICT study. Int J Cardiol 276: 218-223.

89. Zhang $Y$, Liou WW, Gupta $V$ (2015) Modeling of high sodium intake effects on left ventricular hypertrophy. Comput Biol Med 58: 31-39.

90. Ferreira DN, Katayama IA, Oliveira IB, Rosa KT, Furukawa LNS, et al. (2010) Salt-induced cardiac hypertrophy and interstitial fibrosis are due to a blood pressure-independent mechanism in Wistar rats. J Nutr 140: 1742-1751.

91. Le Corvoisier P, Adamy C, Sambin L, Crozatier B, Berdeaux A, et al. (2010) The cardiac renin-angiotensin system is responsible for highsalt diet-induced left ventricular hypertrophy in mice. Eur J Heart Fail 12: 1171-1178.

92. Chang RL, Nithiyanantham S, Huang CY, Pai PY, Chang TT, et al. (2019) Synergistic cardiac pathological hypertrophy induced by high-salt diet in IGF-IIRalpha cardiac-specific transgenic rats. PLoS One 14: e0216285.

93. Lang $\mathrm{H}$, Xiang Y, Ai Z, You Z, Jin X, et al. (2018) UCP3 Ablation Exacerbates High-Salt Induced Cardiac Hypertrophy and Cardiac Dysfunction. Cell Physiol Biochem 46: 1683-1692.

94. Harmsen E, Leenen FH (1992) Dietary sodium induced cardiac hypertrophy. Can J Physiol Pharmacol 70: 580-586.

95. Dhingra R, Pencina MJ, Benjamin EJ, Levy D, Larson MG, et al. (2004) Cross-sectional relations of urinary sodium excretion to cardiac structure and hypertrophy. The Framingham Heart Study. Am J Hypertens 17: 891-896.

96. Lucko AM, Doktorchik C, Woodward M, Cogswell M, Neal B, et al (2018) Percentage of ingested sodium excreted in 24-hour urine collections: A systematic review and meta-analysis. J Clin Hypertens (Greenwich) 20: 1220-1229.

97. Mahajan A, Rodan AR, Le TH, Gaulton KJ, Haessler J, et al. (2016) Trans-ethnic Fine Mapping Highlights Kidney-Function Genes Linked to Salt Sensitivity. Am J Hum Genet 99: 636-646.

98. Schmidlin O, Forman A, Leone A, Sebastian A, Morris RC Jr (2011) Salt sensitivity in blacks: evidence that the initial pressor effect of $\mathrm{NaCl}$ involves inhibition of vasodilatation by asymmetrical dimethylarginine. Hypertension 58: 380-385.

99. Anand SS, Hawkes C, de Souza RJ, Mente A, Dehghan M, et al (2015) Food Consumption and its Impact on Cardiovascular Disease: Importance of Solutions Focused on the Globalized Food System: A Report From the Workshop Convened by the World Heart Federation. J Am Coll Cardiol 66: 1590-1614.

100. Tapsell LC, Neale EP, Satija A, Hu FB (2016) Foods, Nutrients, and Dietary Patterns: Interconnections and Implications for Dietary Guidelines. Adv Nutr 7: 445-454

101. Jacobs T (2011) Food Synergy: The Key to Balancing the Nutrition Research Effort. Public Health Rev 33: 507-529.

102. Annis C, Phanzu KP, Moussa S, El Hattaoui M, Dounia B, et al. (2017) Lifestyle Changes for Abdominal Obesity Prevention and Encouraging Fruit Consumption May Be Beneficial in Preventing Left Ventricular Hypertrophy in Sub-Saharan African and Maghreb. World I Cardiovasc Dis 7: 11. 
103. Hodgson JM, Prince RL, Woodman RJ, Bondonno CP, Ivey KL, et al. (2016) Apple intake is inversely associated with all-cause and disease-specific mortality in elderly women. Br J Nutr 115: 860-867.

104. Griffiths K, Aggarwal BB, Singh RB, Buttar HS, Wilson D, et al. (2016) Food Antioxidants and Their Anti-Inflammatory Properties: A Potential Role in Cardiovascular Diseases and Cancer Prevention. Diseases 4: 28.

105. Maulik SK, Kumar S (2012) Oxidative stress and cardiac hypertrophy: a review. Toxicol Mech Methods 22: 359-366.

106. Haring B, Wang W, Fretts A, Shimbo D, Lee ET, et al. (2017) Red meat consumption and cardiovascular target organ damage (from the Strong Heart Study). J Hypertens 35: 1794-800.

107. Unger T, Borghi C, Charchar F, Khan NA, Poulter NR, et al. (2020) 2020 International Society of Hypertension Global Hypertension Practice Guidelines. Hypertension 75: 1334-1357.

108. Whelton PK, Carey RM, Aronow WS, Casey DE Jr, Collins KJ, et al. (2018) 2017 ACC/AHA/AAPA/ABC/ACPM/AGS/APhA/ASH/ASPC/ NMA/PCNA Guideline for the Prevention, Detection, Evaluation, and Management of High Blood Pressure in Adults: A Report of the American College of Cardiology/American Heart Association Task Force on Clinical Practice Guidelines. J Am Coll Cardiol 71: 21992269.
109. Williams B, Mancia G, Spiering W, Agabiti Rosei E, Azizi M, et al. (2018) 2018 ESC/ESH Guidelines for the management of arterial hypertension. Eur Heart J 39: 3021-3104.

110. Arnett DK, Blumenthal RS, Albert MA, Buroker AB, Goldberger $Z D$, et al. (2019) 2019 ACC/AHA Guideline on the Primary Prevention of Cardiovascular Disease: Executive Summary: A Report of the American College of Cardiology/American Heart Association Task Force on Clinical Practice Guidelines. Circulation 140: e563-e595.

111. Rippe JM (2019) Lifestyle Strategies for Risk Factor Reduction, Prevention, and Treatment of Cardiovascular Disease. Am J Lifestyle Med 13: 204-212. 